\title{
A pilot study to assess the feasibility of endoscopic placement of a transurethral urinary balloon catheter in male sheep cadavers
}

\author{
Marlene Sickinger ${ }^{1,2^{*}} \mathbb{D}$, Reto Neiger ${ }^{3,4}$ and Axel Wehrend ${ }^{1}$
}

\begin{abstract}
Surgery of obstructive urolithiasis in small ruminants is often unsatisfactory due to postoperative development of strictures. The present study aimed to establish an endoscopic technique for the placement of a transurethral urinary catheter into the bladder of rams. This catheter was used as a removable stent-like drainage. The procedure was performed in three sheep rams that were euthanized and placed for surgery in $45^{\circ}$ Trendelenburg position. In one ram, cystotomy was performed via right paramedian laparotomy. A $3 \mathrm{~mm}$ flexible fiberscope was introduced into the urinary bladder and advanced via urethra to the tip of the penis. Placing a guide wire through the endoscopic working channel into the urethra enabled the retrograde insertion of a transurethral urinary catheter into the bladder. In two rams, retrograde insertion of a fiberscope was performed. Again, a guidewire was used to insert a balloon catheter into the bladder. Paramedian right laparotomy was performed to ascertain the correct position of the balloon. Both techniques, antero- and retrograde endoscopy, were possible and could be successfully performed. Mucous membranes and urinary microliths were easily observed. Repeated advancing of the endoscope or the catheter resulted in marked damage of the mucous membranes. The patency of the urethra may be restored by means of endoscopic placement of a transurethral catheter in male small ruminants. The applicability and clinical outcome of this procedure as well as the effects on stricture formation should be further examined with controlled clinical studies.
\end{abstract}

Keywords: Endoscopy, Procedure, Small ruminants, Urolithiasis

\section{Findings}

Partial or complete obstruction of the urethra with potentially live threatening complications such as marked hyperkalaemia, hydronephrosis and peritonitis are potential problems of urolithiasis in small ruminants [1, 2]. Predisposing factors for the development of uroliths, such as species, breed predispositions and castration as well as dietary risk factors have been identified [3-5]. If untreated, complete urethral obstruction often results in a fatal outcome and animals are commonly presented in an emergency setting $[2,6]$. Although many surgical techniques for relieve of obstructive urolithiasis have been established [7], long-term success rates are still

\footnotetext{
*Correspondence: Marlene.Sickinger@vetmed.uni-giessen.de

${ }^{1}$ Clinic for Obstetrics, Gynecology and Andrology of Large and Small

Animals, Justus-Liebig-University of Giessen, 35392 Giessen, Germany

Full list of author information is available at the end of the article
}

unsatisfactory [8]. One of the main problems in small ruminants with urolithiasis is a stricture formation of the urethra after surgical intervention [9]. This complication commonly results in a relapse due to newly formed uroliths that again obliterate the urethra. The aim of the present study was to establish an endoscopic method that enables the placement of a transurethral urinary catheter into the urinary bladder. This then serves as continuous urine drainage and should prevent stricture formation as it works like a removable urethral stent (Figs. 1, 2).

The endoscopic technique was performed in three 6-months-old male intact sheep rams of different breeds (Coburger, Coburger-crossbred and Black Milksheepcrossbred). The median body weight was $38.1 \mathrm{~kg}$ with a range from 34.8 to $41.8 \mathrm{~kg}$. Animals were euthanized with sodium-pentobarbital $\left(500 \mathrm{mg} / \mathrm{mL}\right.$; Release ${ }^{\circledR}$, WDT, Garbsen, Germany) immediately before starting the procedure. The study was performed in accordance with 

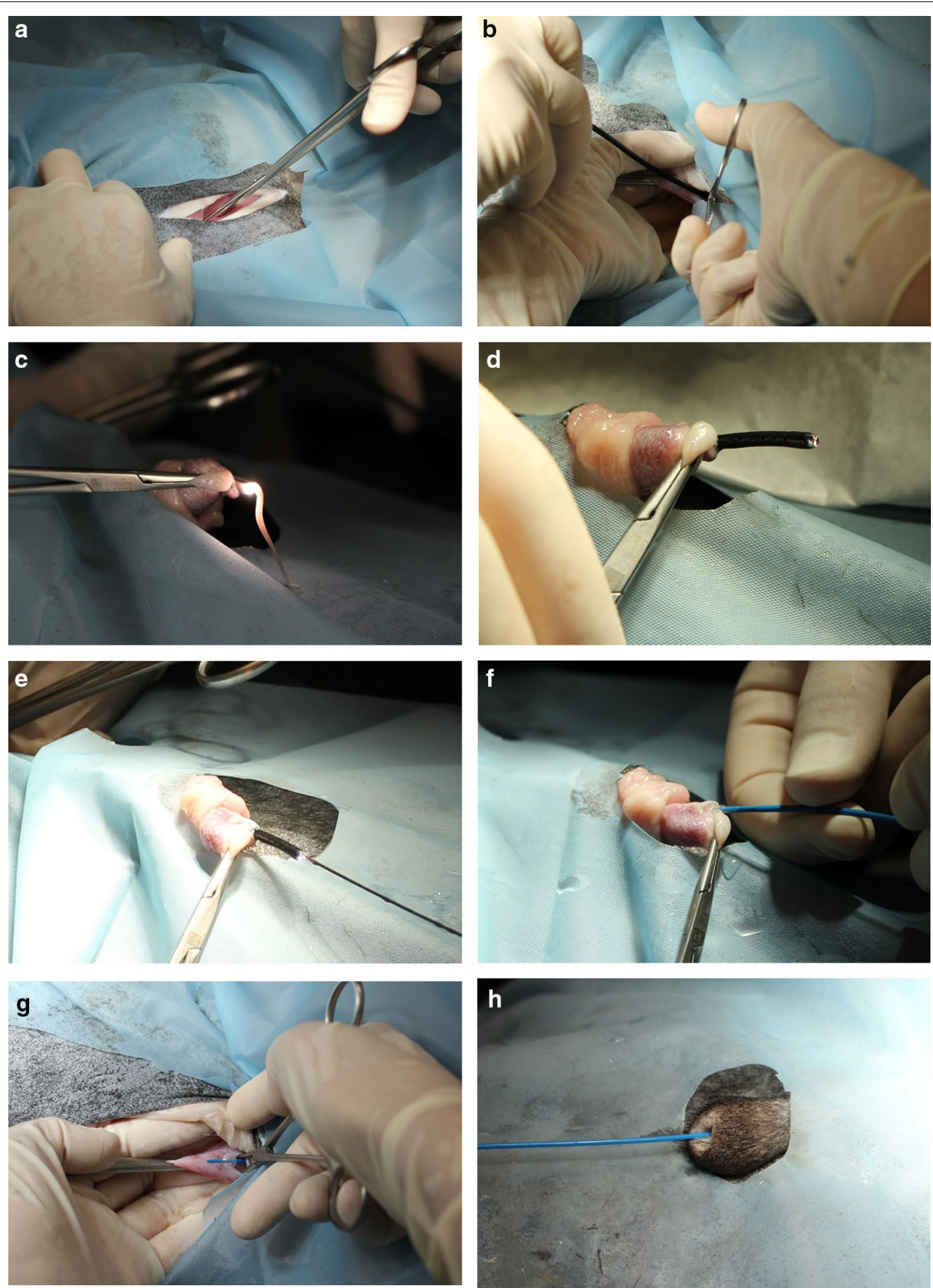

Fig. 1 Anterograde urethroscopy and retrograde placement of a transurethral balloon-catheter into the urinary bladder. a Paramedian right laparotomy. $\mathbf{b}$ Insertion of the fiberscope into the urinary bladder via stab incision. $\mathbf{c}$ Fiberscope at the tip of the penis. $\mathbf{d}$ Protrusion after removing the urethral process. e Introduction of a guide wire into the working channel of the fiberscope with subsequent. $\mathbf{f}$ Introduction of the balloon-catheter via guide wire into the urinary bladder $(\mathbf{g})$. $\mathbf{h}$ Catheter in situ 

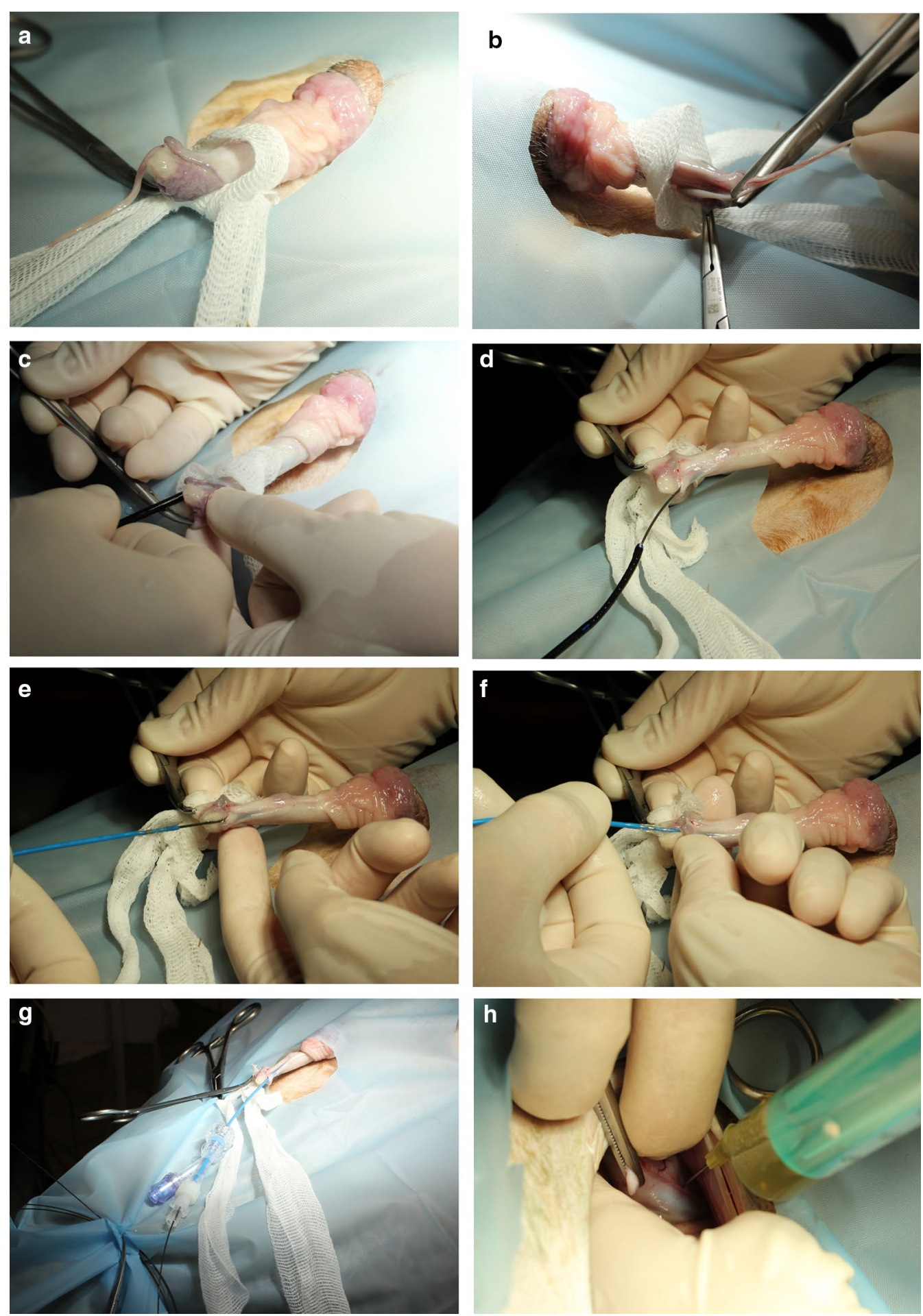

Fig. 2 Retrograde urethroscopy and placement of the balloon-catheter. a Protrusion of the penis out of the prepuce. $\mathbf{b}$ Amputation of the urethral process. $\mathbf{c}$ Introduction of the fiberscope into the urethra. $\mathbf{d}$ Placing of guide wire into the urinary bladder under endoscopic control. $\mathbf{e}-\mathbf{g}$ Introduction of the urethral catheter via guide wire into the urethra and urinary bladder. $\mathbf{h}$ Diagnostic laparotomy to ascertain the correct position of the balloon-catheter in the trigone region 
national legislation and with the approval of the local ethics committee of the Justus-Liebig-University of Giessen, Germany (Number of compliancy: 600_M/2016). The animals were prepared for surgery and positioned in dorsal recumbency in a $45^{\circ}$-Trendelenburg position (head lower than body).

In one ram, a paramedian laparotomy was performed and the urinary bladder was advanced. After removal of urine via cystocentesis, a flexible fiberscope ( $3 \mathrm{~mm}$ diameter, $1 \mathrm{~m}$ long; Storz, Tuttlingen, Germany) was advanced via cystotomy into the urethra. The mucosal surface of the urethra was evaluated and urinary microliths were identified. The endoscope was then pushed anterograde through the urethra. The urethral process was amputated to enable the endoscope to exit the urethra. A guide wire was then placed through the working channel of the endoscope. After removing the fiberscope, a ureteral occlusion balloon catheter $(\mathrm{CH} \mathrm{5}$, balloon $1 \mathrm{~mL}$, length $75 \mathrm{~cm}$; Urotech, Achenmühle, Germany) was placed retrograde over the guide wire into the urinary bladder. The balloon was blocked with $1 \mathrm{~mL} \mathrm{NaCl}$. Aspiration and flushing of the urinary bladder through this catheter was easy.

In two rams, placed also in a $45^{\circ}$ Trendelenburg position, direct retrograde cystoscopy was achieved with the same endoscope after amputating the urethral process. Passage of the urethral recess at the arcus ischiadicus during retrograde urethroscopy could only be accomplished using a Seldinger technique with the guide wire in the working channel as guide. The guide wire was left in place and after removal of the fiberscope, a $\mathrm{CH} 5$ occlusion balloon catheter was placed retrograde into the bladder. Flushing and aspiration urine was equally possible.

The complete procedure could be performed in all three animals with anterograde or retrograde insertion of the fiberscope through the entire urethra. Repeated insertion and protrusion of the catheter or the fiberscope, respectively, led to marked damage of the mucosal surface of the urethra and to an enhancement of resistance when pushing the fiberscope or catheter forward. An in-depth evaluation of the urinary bladder with the small diameter fiberscope in a retrograde fashion was not possible because of insufficient illumination.

To our knowledge, this is the first study performing an endoscopy-guided catheterization of the extremely long and narrow urethra of small ruminants. In contrast to other studies, no urethrotomy was performed and a balloon catheter was placed directly into the urinary bladder. This represents a modification and combination of existing surgical techniques [10-16]. The advantage of our technique is that the placement of the urinary catheter helps to allow passage of urine, and to keep the urethra open in a fashion similar to a removable stent. Surgical techniques always have the risk of stricture formation and special procedures like buccal mucosal graft urethroplasty for reversal of an urethrostomy [9] are not suitable for most clinicians. Clinical cases will now need to be treated with this method to evaluate it in a practical setting and assess the development of strictures. In contrast to other studies $[9,17]$, this study indicates that this technique will be of high impact for future surgical interventions in rams with obstructive urolithiasis.

Endoscopic removal of uroliths from the urethra of male ruminants has been reported previously. The authors used endoscopy-guided laser lithotripsy in 15 goats [10] and one bull [18] with restored patency of the urethra. Due to necessary equipment and cost associated with endoscopy and lithotripsy, this method seems more suitable for companion animals [19] than being acceptable for livestock animals. However, sheep and goats are being kept more and more as companion animals, thus higher medical costs are probably accepted by the owners.

A possible drawback of our technique in anaesthetized rams could be that the long, narrow and curved urethra might not be easily stretched to accommodate the fiberscope. Using epidural anaesthesia might allow to advance the penis and to stretch the sigmoid flexure even if the animal is in dorsal recumbency [20].

In summary, endoscopic placement of a transurethral balloon-catheter into the urinary bladder is possible in an anterograde and retrograde fashion. This should decrease stricture formation due to a stent-like device into the urethra. Although this procedure is promising, further research in anaesthetized rams with urethral obstruction is necessary and must be the aim of future studies.

\section{Acknowledgements \\ Not applicable.}

\section{Prior publication}

Data have not been published previously.

\section{Authors' contributions}

MS and RN performed the endoscopy in this pilot study. MS developed the study design. AW supervised the ethical standards and was responsible for the communication with the local authority. All authors read and approved the final manuscript.

\section{Funding}

This research did not receive any specific grant from funding agencies in the public, commercial, or not-for-profit sectors.

\section{Availability of data and materials}

The datasets used and/or analysed during the current study are available from the corresponding author on reasonable request.

\section{Ethics approval and consent to participate}

The study was performed in accordance with national legislation and with the approval of the local ethics committee of the Justus-Liebig-University of Giessen, Germany (Number of compliancy: 600_M/2016). 


\section{Consent for publication}

Not applicable.

\section{Competing interests}

The authors declare that they have no competing interests.

\section{Author details}

${ }^{1}$ Clinic for Obstetrics, Gynecology and Andrology of Large and Small Animals, Justus-Liebig-University of Giessen, 35392 Giessen, Germany. ${ }^{2}$ Present Address: Clinic for Ruminants, Internal Medicine and Surgery, Justus-LiebigUniversity of Giessen, 35392 Giessen, Germany. ${ }^{3}$ Clinic for Companion Animals Internal Medicine, Justus-Liebig-University of Giessen, 35392 Giessen, Germany. ${ }^{4}$ Present Address: Hofheim Animal Hospital, 65719 Hofheim, Germany.

Received: 4 June 2019 Accepted: 27 October 2019

Published online: 04 November 2019

\section{References}

1. Van Metre DC, Fubini SL. Ovine and caprine urolithiasis: another piece of the puzzle. Vet Surg. 2006;35:413-6.

2. Kümper H. Urolithiasis in male sheep and goats. Clinical picture, therapeutic possibilities and prognostic evaluation (in German). Tierarztl Prax. 1994;22:234-41.

3. Bani Ismail ZA, Al-Zghoul MF, Al-Majali AM, Khraim NM. Effects of castration on penile and urethral development in Awassi lambs. Bulg J Vet Med. 2007;10:29-34.

4. Crookshank HR, Robbins JD, Kunkel HO. Relationship of dietary mineral intake to serum mineral level and the incidence of urinary calculi in lambs. J Anim Sci. 1967;26:1179-85.

5. Nwaokorie EE, Osborne CA, Lulich JP, Fletcher TF, Ulrich LK, Koehler LA, Buettner MT. Risk factors for calcium carbonate urolithiasis in goats. J Am Vet Med Assoc. 2015;247:293-9.

6. Dühlmeier R, Zibell G, von Altrock A, Roth C, Schroeder C, Thies K, Ganter M. Urolithiasis in small ruminants-methods of treatment and recovery (in German). Tierarztl Prax. 2007;35:175-82.

7. Sickinger $\mathrm{M}$. Therapeutic options of obstructive urolithiasis in small ruminants (in German). Tierarztl Prax. 2019;47:111-5.

8. Ewoldt JM, Anderson DE, Miesner MD, Saville WJ. Short- and long-term outcome and factors predicting survival after surgical tube cystostomy for treatment of obstructive urolithiasis in small ruminants. Vet Surg 2006:35:417-22.

9. Gill MS, Sod GA. Buccal mucosal graft urethroplasty for reversal of a perineal urethrostomy in a goat wether. Vet Surg. 2004;33:382-5.

10. Halland SK, House JK, George LW. Urethroscopy and laser lithotripsy for the diagnosis and treatment of obstructive urolithiasis in goats and potbellied pigs. J Am Vet Med Assoc. 2002;220:1831-4.

11. Franz S, Dadak AM, Schöffmann G, Coppens P, Khol JL, Baumgartner W, Dupre G. Laparoscopic-assisted implantation of a urinary catheter in male sheep. J Am Vet Med Assoc. 2008;232:1857-62. https://doi.org/10.2460/ javma.232.12.1857.

12. Fortier LA, Gregg AJ, Erb HN, Fubini SL. Caprine obstructive urolithiasis: requirement for 2 nd surgical intervention and mortality after percutaneous tube cystostomy, surgical tube cystostomy, or urinary bladder marsupialization. Vet Surg. 2004;33:661-7.

13. Fazili MR, Malik HU, Bhattacharyya HK, Buchoo BA, Moulvi BA, Makhdoomi DM. Minimally invasive surgical tube cystotomy for treating obstructive urolithiasis in small ruminants with an intact urinary bladder. Vet Rec. 2010;166:528-31.

14. Ewoldt JM, Jones ML, Miesner MD. Surgery of obstructive urolithiasis in ruminants. Vet Clin North Am Food Anim Pract. 2008;24:455-65.

15. Reppert EJ, Streeter RN, Simpson KM, Taylor JD. Retrograde catheterization of the urinary bladder in healthy male goats by use of angiographic catheters. Am J Vet Res. 2016;77:1295-9.

16. Haven ML, Bowman KF, Engelbert TA, Blikslager AT. Surgical management of urolithiasis in small ruminants. Cornell Vet. 1993;83:47-55.

17. Van Metre DC. Urolithiasis. In: Fubini SL, Ducharme NG, editors. Farm animal surgery. St Louis: Saunders; 2004. p. 534-47.

18. Streeter RN, Washburn KE, Higbee RG, Bartels KE. Laser lithotripsy of a urethral calculus via ischial urethrotomy in a steer. J Am Vet Med Assoc. 2001;219:640-3.

19. Heilmann RM. Minimally invasive interventional techniques involving the urogenital tract in dogs and cats (in German). Tierarztl Prax. 2016;44:105-15.

20. Nuss K, Schwarz A, Ringer S. Local anaesthesia in ruminants (in German). Tierarztl Prax. 2017:45:159-73.

\section{Publisher's Note}

Springer Nature remains neutral with regard to jurisdictional claims in published maps and institutional affiliations.
Ready to submit your research? Choose BMC and benefit from:

- fast, convenient online submission

- thorough peer review by experienced researchers in your field

- rapid publication on acceptance

- support for research data, including large and complex data types

- gold Open Access which fosters wider collaboration and increased citations

- maximum visibility for your research: over 100M website views per year

At BMC, research is always in progress.

Learn more biomedcentral.com/submissions 